\title{
РИТОРИКА АГЕНТОВ СОЦИАЛЬНОГО КОНТРОЛЯ В ОТНОШЕНИИ ПРОФИЛАКТИКИ ПРОТИВОПРАВНОГО ПОВЕДЕНИЯ МОЛОДЕЖИ
}

Зарубежные исследования свидетельствуют о низкой эффективности профилактического социального контроля. В России подтверждением тому являются негативные тенденции развития противоправного поведения, которые, в первую очередь, выражаются в его росте, омоложении и феминизации. Изучение причин неэффективности профилактики можно проводить не только на основе рассмотрения негативных результатов профилактического воздействия, но и путем анализа оценок, даваемых агентами социального контроля. Для этого предлагается осмыслить предмет в рамках социального конструктивизма, который рассматривает социальный контроль как коммуникацию в социальных взаимодействиях, предполагающую передачу некоторой информации, идей, конструктов социальной реальности посредством знаков и символов. Для изучения коммуникации использован метод деконструкции риторики агентов профилактики (работников полиции, школы, соцзащиты). Автор обрисовывает теоретические рамки изучения риторик, представляет результаты анализа транскриптов фокусированного интервью с экспертами. В качестве экспертов выступили представители полиции, школы, государственных и негосударственных учреждений социальной защиты населения, занимающихся профилактикой противоправного поведения. Деконструированы риторики, касающиеся взаимодействия агентов профилактической работы с молодежью. Исследование показало, что состояние этой деятельности описывается агентами контроля либо в идиоме опасности, либо с использованием лейтмотивов бедствия. У представителей полиции и школы субъективное восприятие угрозы связано с неэффективной деятельностью соответствующих учреждений и недостаточной заинтересованностью родителей. Эксперты использовали также конструкты

Татьяна Владимировна Шипунова - д.с.н., доцент, профессор, Санкт-Петербургский государственный университет, Санкт-Петербург, Россия. Электронная почта: shtatspb@yandex.ru 
риторики наделения правом, которые ассоциированы с расширением полномочий самих агентов контроля. Представители государственных и негосударственных организаций социальной защиты при описании состояния профилактической деятельности чаще используют лейтмотивы бедствия. Они связывают угрозы с недостаточным вниманием государства к проблеме профилактики противоправного поведения молодежи. Это выражается в скудной финансовой поддержке, непродуманности законов, сокращении сотрудников, неоправданно жестком контроле деятельности агентов профилактической работы.

Ключевые слова: профилактика противоправного поведения, агенты профилактики, риторическая деконструкция, риторические идиомы, лейтмотивы

DOI: $10.17323 / 727-0634-2019-17-4-525-538$

Исследования профилактического социального контроля в разных странах показывает, что его эффективность невысока. Так, широкомасштабное и долговременное изучение влияния социальных программ на делинквентное поведение подростков, осуществленное в конце прошлого века в США, продемонстрировало неэффективность профилактического воздействия (Грэхэм, Беннетт 1995). Подтвердили это и более поздние исследования, в результате которых был сделан вывод: отдельные программы профилактики не только не нужны, но даже вредны (Eisner et al. 2008: 13-25). В отличие от США, эффективность немецких превентивных программ стала изучаться позднее - в конце 1990-х гг. Одно из исследований (1997-2005 г.г.), посвященное влиянию организованного досуга на насилие среди молодежи, дало более обнадеживающий результат: использование специальных программ в детских садах и школах привело к тому, что, во-первых, снизилось число жертв насилия среди детей и подростков с 23,6\% до 19,8\%, а, во-вторых, число насильников среди детей и подростков сократилось с 24,9\% до 16\% (Pfeifer, Baier 2008: 562).

В России аналогичные исследования отсутствуют. Однако о неэффективности и проблематичности профилактического социального контроля свидетельствуют негативные тенденции, связанные с ростом преступности (Ефимовский, Стебенева 2015:84), увеличением числа потребителей наркотиков и алкоголя среди молодежи, особенно несовершеннолетней (Уполномоченный по правам человека в Санкт-Петербурге 2016:251-254), расширением феминизации противоправного поведения (Ображиев 2015:24).

Для понимания причин неэффективности социального контроля необходимо исследовать не только его последствия, но и отношение агентов (социальных институтов, организаций) контроля к профилактической деятельности. К агентам социального контроля традиционно относят официальные институты (полиция, учреждения социального обслуживания, отдел по делам несовершеннолетних, сфера образования), осуществляющие 
формальный контроль, и институты, реализующие неформальный социальный контроль (семья, профильные общественные, религиозные и правозащитные организации). Однако список этих агентов гораздо шире. К ним можно отнести, например, различные субкультурные группы, естественные кооперации (соседскую общность, друзей), социальные сети и сайты в Интернете, молодежные движения (спортивные, музыкальные, досуговые) и пр.

В предлагаемой статье обсуждается работа трех агентов социального контроля: полиции, школы и учреждений социальной защиты. Основной исследовательский вопрос - определение ситуации взаимодействия с разными агентами социального контроля (преимущественно с официальными социальными институтами) методом риторической деконструкции. В coответствие с исследовательским вопросом выстроена структура статьи: сначала описываются теоретические основания исследования риторики, опирающиеся на методологию Питера Ибарры и Джона Китсьюза, затем представляются результаты анализа лейтмотивов риторик представителей социального контроля, в заключении статьи делаются обобщения.

\section{Теоретические рамки изучения риторик}

Основные теоретики социального конструктивизма утверждали, что власть стремится производить социальную реальность через организацию деятельности институтов социального контроля (Бергер, Лукман 1995: 195). Конструктивистская методология дает возможность говорить о социальном контроле как о специфической коммуникации в социальных взаимодействиях, в которых участники конструируют смыслы, определяя тем самым социальную реальность. Изучение конструктов, с помощью которых участники коммуникации определяют ситуацию, позволяет понять «каким образом люди наделяют смыслом свой мир» (Бест 2001: 164), и конкретно сферу профессиональной деятельности. Анализ конструктов в данном случае имеет целью подтверждение тезиса, что, несмотря на независимость социальных структур от участников социального взаимодействия, они не в состоянии существовать без субъектов деятельности, которые не только формируются сами, но и формируют общество (Штомпка 1996).

Выделение и анализ компонентов конструктов производится разными методами. В этом исследовании применяется логика, предложенная Малькольмом Спектором и Джоном Китсьюзом. Они делают акцент на анализе риторических утверждений относительно предполагаемых условий деятельности, ее организации и требований «искоренения, улучшения или какого-либо другого изменения некоторого условия» (Спектор, Китсьюз 2001: 161). При этом авторы предлагают использовать метод риторической деконструкции, восстанавливающей смыслы исходного текста с целью выявления тех из них, что способны создать целостность при определении той или иной ситуации. 
Объектом анализа может быть любой текст, отражающий позицию участников социального взаимодействия: газетные статьи, отчеты, доклады, транскрибированные интервью. Задача социолога состоит в том, чтобы превратить лингвистическую продукцию участников, представляющих собой конструкции первого порядка (просторечные высказывания), в конструкции второго порядка (выявленные риторики дискурса). Это происходит в результате «реконструкции просторечных (vernacular) ocнований и составных частей дискурса социальных проблем» (Ибарра, Китсьюз 2007: 61). Одним из условий ее проведения является анализ того, «каким образом утверждения-требования одобряются (licensed) и выдвигаются» (Там же: 62). Также обращается внимание на необходимость выделения условий-категорий, в которых участники типизируют активности и процессы, чтобы в дальнейшем использовать их в «практических контекстах с целью производства значимых (meaningful) описаний и оценок социальной реальности» (Там же: 63).

Важно прояснить названные выше термины. Просторечные ресурсы «включают в себя риторические идиомы, интерпретативные практики и особенности среды, отличающие выдвижение утверждений-требований как класс явлений» (Там же: 67). Проводя деконструкцию, исследователь сталкивается с необходимостью выявления риторик, которые создают рамки различения устойчивых и осмысленных образцов речи. При этом под риторикой понимается изучаемая тематическая и смысловая область. Авторы предлагают использовать четыре измерения риторик: риторические идиомы, контр-риторики, лейтмотивы и стили выдвижения утверждений-требований (Там же: 69). Каждое из этих понятий дает возможность деконструировать риторику в разных срезах. Так, риторические идиомы определяются как дефинициональные комплексы языка; анализ контрриторики дает представление о позиции говорящего в отношении использования тех или иных категорий; изучение лейтмотивов, представляющих собой распространенные фразы (или «фигуры речи»), помогает выявить «описания динамики условия-категории или реакции на него»; фиксация стиля выдвижения утверждений-требований «способствует переносу нашего внимания от языка, на котором сформулированы утверждения-требования, к манере и тональности» (Там же: 70-71).

Каждой риторической идиоме соответствует набор терминов, позволяющих выявить общий смысл определения проблемы. Список терминов может быть дополнен терминами кроссидеоматического словаря, т.е. образными выражениями, характеризующими социальную проблему: «чума XXI века», «кризис», «трагедия», «бомба с заведенным часовым механизмом», «верхушка айсберга». Ибарра и Китсьюз (2007: 72-84) предложили выделить пять риторических идиом, сопровождающихся набором ключевых терминов. Например, риторике утраты соответствуют позитивные термины «невинность», «красота», «чистота», «ясность», «наследие», «культура», 
а также негативные термины-антагонисты, имеющие целью обесценивание: «грех», «упадок», «хаос». Риторика наделения правом (rhetoric of entitlement) имеет в своем арсенале словарь из таких терминов, как: «доступ к самовыражению», «свобода», «жизненный стиль», «различия», «выбор», «терпимость», «предоставление возможностей», «мультикультурный». Словарь негативных терминов включает слова: «дискриминация», «нетерпимость», «угнетение», «эйджизм». Идиома опасности также задействует позитивные термины: «гигиена», «профилактика», «фитнес»; и негативные: «болезнь», «патология», «эпидемия», «риск», «заражение», «угроза здоровью». В условиях обеспокоенности по поводу эксплуатации, манипулирования кемлибо используется риторика неразумности, словарь которой наполняется терминологией, описывающей эти явления и их последствия. В данной риторике часто артикулируются проблемы образования, усиления контроля со стороны различных институтов. Риторика бедствия включает в себя метафоры и другие практики аргументации, с помощью которых формируется образ катастрофы.

Некоторые положения и выводы работы Ибарры и Китсьюза носят дискуссионный характер. Например, утверждения-требования не обязательно должны быть явными, они могут содержаться в оценках и (непрямом) выражении отношения к некоторым элементам проблемы. Кроме того, арсенал терминов, при помощи которых конструируются риторики, может быть существенно расширен за счет использования специфической профессиональной терминологии и обыденных выражений, наделенных смыслом в конкретном культурном контексте. Впрочем, эти замечания не являются принципиальными для этого исследования, проведенного в рамках проекта «Положение и риски девиантности молодежи, проживающей в мегаполисе (на примере Санкт-Петербурга)», поскольку методология авторов доказала свой значительный аналитический потенциал.

Целью исследования было изучение риторик, используемых агентами профилактического социального контроля для определения взаимодействий с другими контролирующими агентами. Фокусированные интервью с экспертами (сотрудниками организаций контроля) проанализированы с использованием метода риторической деконструкции. Для этого рассмотрены идиомы и лейтмотивы, которые используются экспертами для описания взаимодействия друг с другом. К лейтмотивам представителей разных агентов контроля были отнесены конструкции, наиболее полно и эмоционально отражающие мнение участников интервью. Процедура изучения текстов интервью состояла в следующем: выделены группы в зависимости от принадлежности к организации контроля (кто говорит); рассматривались выражения, слова, термины, с помощью которых определяется ситуация (как говорят); посредством сопоставления языковых единиц с лейтмотивами и терминами идентифицировалась риторическая идиома, в которой разворачивается определение ситуации и ее проблематизация (т.е. устанав- 
ливался смысл утверждения - что говорят). При сравнении единиц текста с лейтмотивами и терминами учитывались просторечные выражения, ассоциированные по смыслу с образцами значений. Кроме того, соблюдалось методическое требование, указывающее, что «строгий конструкционистский анализ фокусируется исключительно на риторике, отказываясь от каких-либо предположений о характере, масштабе, последствиях и даже о самом существовании ситуаций, в отношении которых разворачивается риторика» (Ясавеев 2016: 50).

\section{Лейтмотивы риторик агентов социального контроля}

Участники фокусированного интервью представляли три агента профилактического социального контроля Санкт-Петербурга: полицию, школу и учреждения социальной защиты. Всего в исследовании участвовало десять женщин и пять мужчин, стаж работы в среднем составил 14 лет. От полиции экспертами выступили сотрудники службы участковых, полиции по охране общественного порядка и отдела участковых уполномоченных по делам несовершеннолетних трех районов Петербурга (всего 3 чел.). Школа представлена преподавателем лицея (классным руководителем) и социальным педагогом. Наибольшее число экспертов было из учреждений социальной защиты (государственных и негосударственных). Шесть экспертов - из государственных учреждений социальной защиты (Центр социальной помощи семье и детям одного из городских районов, Подростково-молодежный центр и Городской центр, деятельность которого напрямую связана с профилактикой асоциальных явлений среди молодежи). Из негосударственных учреждений согласились участвовать специалисты (4 чел.), работающие с несовершеннолетней молодежью, имеющей проблемы с законом, опыт потребления наркотиков, алкоголя, табака, ранних сексуальных связей и проживающих в неблагополучных семьях. Этот агент социального контроля представлен двумя центрами, в которых проходят социальную адаптацию подростки в возрасте 12-18 лет. В интервью участвовали как руководители подразделений, так и специалисты по социальной работе с молодежью.

Экспертам предложено оценить деятельность агентов, с которыми они взаимодействуют при осуществлении профилактики правонарушений молодежи. Данный вопрос направлен на прояснение условий-категорий и их проблематизацию, помогающую выявить смысл требований, выдвигаемых агентами профилактической деятельности (Ибарра, Китсьюз 2007: 72). Для всех участников интервью основным условием-категорией было взаимодействие, которое, однако, уточнялось в зависимости от специфики деятельности агента профилактики и особенностей профессиональной коммуникации с представителями разных учреждений. Следует отметить, что все эксперты рассматривают взаимодействие с партнерами по профилактической деятельности как необходимое условие ее эффективности. 
Несмотря на то что в интервью упомянуты факты сотрудничества, не имеющие негативной окраски, наша задача - выяснение проблем, возникающих в процессе взаимодействия.

Представители полиции описывают специфические условия «предупреждения преступности». Дальнейшая спецификация условий зависит от того, что именно определяет их совместную деятельность с различными учреждениями и ведомствами. Так, для школы выбираются конструкции: риск, дети «в каком-то непонятном состоянии, наркотическом либо алкогольном», хранение и потребление наркотиков, дети, пропускающие занятия, «неформалы». Условиями-категориями, определяющими взаимодействия с органами опеки и попечительства, по мнению экспертов из полиции, выступают: трудные семьи, насилие и страдания детей. Сoвместная деятельность полиции с учреждениями социальной защиты обусловливается наличием семейного неблагополучия, трудной жизненной ситуацией женщин и детей (например, жестокое обращение в семье), безнадзорностью, плохими условиями проживания детей-мигрантов, социальным сиротством. К позитивным условиями-категориям представители полиции отнесли помощь, защиту, профилактику.

При проблематизации взаимодействия эксперты полиции используют лейтмотивы опасности, которая оформляется в виде внешней угрозы для неэффективности проводимых ими профилактических мероприятий. Например, когда полиция проводит в школе рейды на предмет потребления наркотиков, и появляется предположение, что ученик их употреблял, то его просят сдать анализ мочи, но родители отказываются, и полицейские «не могут их заставить», поскольку существует запрет на проведение таких мероприятий без согласия родителей. Для характеристики взаимодействия с другими агентами используются конструкции: «Школа nыmaется все затихарить»; «не очень хорошо с опекой налажено» (которая не лишает родительских прав в ситуациях, когда полиция считает это необходимым); «агентства занятности подбирают [работу] несложным детям, обычныл детям», но не тем, кто совершает правонарушения; «администрация [одного из районов города] очень благородно дала много лицензий на алкоголь», что привело к продаже пива несовершеннолетним «по незаконию»; «некуда девать взросльх детей от 17 до 18 лет, их никто не берет», потому что приюты «любят сирот маленьких, с которыми нет проблем, а эти семнадцатилетние - проблемные»; население не всегда откликается на просьбу об информировании о случаях или попытках самоубийства, неформалах, «вялотекущихх алкоголиках».

Кроме того, сотрудники полиции используют моральные компетенции для описания отставания возраста наказания от возраста совершения проступков. Для проблематизации употребляются термины: «ответственность», «правовой нигилизм», «неоправданная толерантность», «нежелательный информационный фон», «нетерпимо», «нарушение традиций». 
В итоге рассуждений эксперты-полицейские, используя идиому наделения правом, приходят к выводу о необходимости понижения возраста ответственности за противоправные поступки: «Административную ответственность... - с 14 лет, вместо 16».

Что касается школы, то к условиям-категориям, детерминирующим ее взаимодействие с другими агентами профилактики, учителя отнесли ранние половые связи, насилие в семье, социально опасное положение семьи, малоимущие семьи, курение и потребление алкоголя, «ночныле прогулки» детей. Среди позитивных условий-категорий выделены конструкции: защита интересов ребенка («мы как адвокатыл)). Проблематизация взаимодействия с различными организациями, задействованными в профилактике, начинается с риторики наделения правом с использованием негативных лейтмотивов. Речь идет о том, что у школы отняли функцию воспитания. Для обозначения этого момента и его последствий используются конструкции: «Сейчас у школь руки связаныл», «мы ничего не можем сделать», «у нас нет никаких прав». Для объяснения утверждения используется лейтмотив «чтобы школа была не только обязана, но и имела свои права», в том числе, «в отношении родителей, которых нужно поставить на место» и «чтобы можно было привести человека к ответу» (речь идет о родителях, которые невнимательны к нуждам ребенка). Задействуются также конструкции риторики утраты: «Мы раньше в школе мыли польл. А сейчас не имеем права заставить ребенка дежурить». В связи с этим один из участников интервью утверждает, что в настоящее время слишком много говорится о правах ребенка, «а есть вещии, когда, возможно, не надо спрашивать ребенка и думать о его правах, а просто нужно делать».

В определении проблем профилактики используется и риторика опасности, которая сопровождается, например, рассуждениями о том, что борьба с наркотиками должна проводиться не столько в школе, сколько на другом уровне, для чего сначала следует «навести порядок не только с правоохранительныли органами, но и туда, дальше» («дальше» не конкретизируется). Тестирование в школе на наркотики признается полезным, но унизительным делом. К проблемам, вызывающим опасения для профилактики правонарушений, отнесены также взаимодействия: с родителями, которые «как правило, ничего не хотят» и которые «производят впечатление, что у них тоже задержка психического развития»; с органами опеки, перекладывающими дела на других (приводится пример со случаем насилия в семье: «Я звоню в опеку, прошу прийти... а они не едут»); с Городским центром социальных программ и профилактики асоциальных явлений среди молодежи («особой помощи от них я не вижу, хотя по идее, они должны многое»); с учреждениями, призванными организовывать досуг, поскольку они не могут предложить ничего интересного и бесплатного для детей с делинквентным поведением («бесплатного сейчас почти ничего нет»); с отделом образования, который тянет с ответами на запросы из школ. 
Третья группа, представители государственных учреждений социальной защиты, выделяют следующие условия-категории, направляющие их взаимодействие с другими агентами профилактики: неблагополучие; социально опасное положение семьи; семьи, состоящие на учете в полиции; злоупотребление алкоголем в семьях; жестокое обращение с детьми; уход детей из дома или учебного заведения и бродяжничество; наркопотребление; курение и употребление алкоголя детьми. Выделяются также позитивные условия-категории, обосновывающие направленность деятельности учреждений соцзащиты. При этом используются конструкции: социальное сопровождение семьи («подхватываем»); гуманитарная помощь; мотивация и расширение кругозора; изменения среды («разукрасить мир несовершеннолетнего»); решение конфликтов («работаем как конфликтологи»); изменение у детей отношения к себе; воспитание и образование.

Проблематизация деятельности по профилактике противоправного поведения молодежи имеет более развернутый характер, чем у представителей полиции и школы. Однако одинаковым является вербальное оформление проблем в риторике опасности, исходящей преимущественно от организаций-партнеров профилактической деятельности. Так, указывается, что «отдел физкультуры и спорта» при администрации города редко помогает, к тому же поступают предложения платного характера («все на платной основе»); полиция ставит на учет, но «проблемы не решает». Особо выделен вопрос об организации летнего отдыха несовершеннолетней молодежи с делинквентным поведением. Один из экспертов так описывает ситуацию: «Многие дети, побывав в этих лагерях, становятся еще хуже... приобретают знакомства соответствующие».

Когда речь идет о государственной поддержке профилактической деятельности, представители государственных учреждений социальной защиты переходят к риторике бедствия. Участники отмечают недостаточное внимание государственных органов власти к проблеме профилактики. Это выражается, например, в том, что приходится работать в рамках несовершенного законодательства, что мешает взаимодействию агентов профилактики. Например, «если у ребенка нет документов, ни одна организация не возьмет этого ребенка». Организации боятся надзорных органов, поскольку они не разбираются с ситуацией, а сразу выносят вердикт о несоблюдении требований законодательства (этот момент обозначается лейтмотивом «у нас постоянные перегибы»)). Кроме того, указывается, что «от курирующих организащий сейчас помощь небольшая кризис экономический». Показательно и такое высказывание: «мы последнее время выживаем». Кроме того, эксперты отметили тревожную ситуацию у их партнера по профилактической деятельности в лице подразделения полиции по делам несовершеннолетних (ПДН): сокращение числа сотрудников, «никто не хочет идти туда работать». Связано это, по мнению одного из экспертов, с тем, что нет четко прописанных норм, «чуть что, 
родители сразу бегут в прокуратуру... начинают писать жалобы». Наряду с сокращениями кадров происходит увеличение количества работы («тот объем работы, который был рассчитан на 10-15 человек, сейчас выполняется двумя-тремя»). Опасность может исходить и от родителей, например, родители часто обманывают сотрудников служб, мешая выполнению ими профессиональных функций или ведут себя безответственно. Оценивая ситуацию с профилактикой в целом, один из экспертов из данной группы утверждает: работа в целом налажена, но «бывает так, как в басне про лебедя, рака и щуку».

Наконец, сотрудники негосударственных учреждений социальной защиты, принявшие участие в интервью, при уточнении условий-категорий используют следующие конструкции: гиперопека; нарушение детско-родительских отношений; плохая успеваемость и отношения в школе; заниженная самооценка у детей и враждебное отношение к взрослым, в отношении которых у них сформировалось негативное мнение («понимание, что взрослье всегда врут»), вследствие чего дети становятся дезориентированными. Особое внимание в дискурсе уделяется потреблению наркотиков.

В данной группе экспертов наиболее ясно обозначена риторика бедствия при проблематизации профилактики правонарушений молодежи. В первую очередь, речь идет о финансировании учреждений («скоро все негосударственные организации, которые действительно что-то делают, просто «загнутся»»). Неправительственный сектор наиболее страдает от нехватки финансирования, даже та часть из них, «которые занимаются, по сути, исполнением государственного заказа». Хотя, по мнению одного из экспертов, государственные организации просто не могут выполнять работу негосударственных. Как указывается в тексте интервью, серьезной проблемой является отсутствие законодательной базы по поводу социальной реабилитации. Не спасает положение и новый закон о социальном обслуживании, поскольку по этому закону получается, что «социальные службы вообще не должны заниматься профилактикой». Один из экспертов связывает ситуацию с тем, что в соответствии с новым законом такие работы должны оплачивать регионы, но «какой регион будет себе ещзе накидывать проблем, которые сам же должен будет решать?». Кроме того, недостаточное финансирование негосударственных организаций вызвано, по словам эксперта, ревностью со стороны государственных учреждений социальной защиты: «А что же мы будем давать этим негосударственным, государственные простаивают пустые»?»

Один из экспертов поднял вопрос о дефиците информации, касающейся размеров распространенности правонарушений в городе. По его мнению, информация искажается, утаивается или подается так, что нельзя узнать абсолютные цифры. Например, администрация запрещает «публиковать информацию по бездомным детям, по беспризорнылм». Эксперт со ссылкой на уполномоченного по правам ребенка отметил, что в городе 
при достаточно тяжелой ситуации с потреблением наркотиков, система профилактики наркопотребления серьезно страдает: «Нет реального загородного Центра реабилитации... у нас закрыто отделение для наркозависимыхх. По его словам, при этом тестирование на наркотики в школах показывает высокий процент потребления: «выявляется 32-33\% nотребителей». В оценке взаимодействия со школой используются лейтмотивы, с одной стороны, обличающие плохую работу школы, а с другой - объясняющие этот факт. Например, в случае потребления наркотиков школа «не хочет связываться, потому что... везде директора будут склонять» (и, возможно, будет наложено какое-то взыскание). В таком же ключе проблематизируется взаимодействие с органами опеки.

\section{Заключение}

Исследование показало, что эксперты проблематизируют взаимодействие агентов профилактики преимущественно либо в идиоме опасности, либо с использованием лейтмотивов бедствия. Разница заключается только в том, кого или что рассматривают участники интервью в виде угрозы. Так, представители полиции видят угрозу преимущественно в недостатках работы таких организаций, как школа и органы опеки. Для обоснования понижения минимального возраста наказания они привлекают идиому наделения правом. Представители школы указывают на проблемы во взаимодействии с органами опеки, некоторыми государственными учреждениями социального обслуживания, учреждениями, призванными организовывать досуг, отделом образования. К проблемам, вызывающим опасения по поводу профилактики правонарушений, отнесены также взаимодействия с родителями. Эксперты из школы применяют лейтмотивы риторики наделения правом при описании ограничений воздействия на родителей при воспитании детей. Для обоснования решения данной проблемы привлекаются термины риторики утраты. Сотрудники учреждений социальной защиты, участвовавшие в интервью, проблематизируют ситуацию взаимодействия посредством лейтмотивов опасности и бедствия. Большая опасность, по мнению экспертов данных учреждений, исходит от государства, которое плохо финансирует деятельность агентов профилактики, не создает разумной правовой базы для ее реализации, сокращает штаты организаций при сохранении нагрузки и осуществляет неоправданно широкий контроль деятельности этих учреждений.

Полученные в ходе исследования результаты свидетельствуют о серьезных проблемах, связанных с профилактикой противоправного поведения молодежи. Они тем более значимы, что социальному контролю со стороны полиции, школы и учреждений социальной защиты противостоит влияние со стороны различных сообществ (включая криминальные). В этой борьбе за влияние на молодежь преимущество может оказаться на стороне таких 
сообществ. Думается, что мнение экспертов, определяющих взаимодействие агентов профилактики в риторике опасности, должно насторожить государство и общественность, заставить задуматься об адекватности предпринимаемых усилий по снижению уровня правонарушений молодежи. Учет мнения специалистов способствует решению тех проблем, которые препятствуют взаимодействию агентов контроля, прежде всего, в области правового обеспечения и финансовой поддержки деятельности, обеспечения кадрами (в необходимом количестве), уменьшения чрезмерного контроля этих организаций, пресекающего любые возможности оперативного решения задач, стоящих перед специалистами.

\section{Выражения признательности}

Статья подготовлена при поддержке РГНФ, проект № 15-03-00383.

\section{Список источников}

Бергер П., Лукман Т. (1995) Социальное конструирование реальности. Трактат по соииологии знания. Москва: Медиум.

Бест Д. (2001) Конструкционистский подход к исследованию социальных проблем. С. А. Ерофеев (ред.) Контексты современности - II: Хрестоматия. 2-е изд., перераб. u доn. Казань: Издательство Казанского университета: 164-174.

Грэхэм Дж., Беннетт Т. (1995) Стратегии предупреждения преступности в Европе и Северной Америке. Хельсинки: Европейский институт по предупреждению преступности и борьбе с ней.

Уполномоченный по правам человека в Санкт-Петербурге (2016) Ежегодный доклад уполномоченного по правам ребенка в Санкт-Петербурге за 2015 г. Санкт-Петербург.

Ефимовский А.В., Стебенева Е.В. (2015) Современная преступность: тенденции, причины, прогноз (на примере Санкт-Петербурга). Вестник Санкт-Петербургского университета МВД России, 1 (65): 82-86.

Ибарра П., Китсьюз Дж. (2007) Дискурс выдвижения утверждений-требований и просторечные ресурсы. И.Г. Ясавеев (ред.) Социальные проблемы: конструкииионистское прочтение. Казань: Издательство Казанского университета: 55-114.

Ображиев К.В. (2015) Преступность несовершеннолетних в современной России: основные криминологические параметры. Правовая инициатива, (2): 14-35.

Спектор М., Китсьюз Дж. (2001) Конструирование социальных проблем. С. А. Ерофеев (ред.) Контексты современности - II: Хрестоматия. 2-е изд., перераб. и доп. Казань: Издательство Казанского университета: 160-163.

Штомпка П. (1996) Социология социальных изменений. Москва: Аспект Пресс.

Ясавеев И. (2016) Лейтмотивы властной риторики в отношении российской молодёжи. Сочиологическое обозрение, (3): 49-67.

Eisner M., Ribeaud D., Junger R., Meidert U. (2008) Frühprävention von Gewalt und Aggression. Ergebnisse des Züricher Interventions- und Präventionsprojektes an Schulen. Zürich: Rüegger Verlag.

Pfeifer Ch., Baier D. (2008) Jugendgewalt als Wahlkampfthema. Eine Kriminologische Analyse zum hessischen Landtagswahlkampf des Jahres. Interdisziplinäre Kriminologie. Festschrift für Arthur Kreuzer zum 70. Geburtstag. Zweiter Band. Frankfurt: Verlag für Polizeiwissenschaft: 550-574. 
Tatiana Shipunova

\title{
THE RHETORIC OF THE AGENTS OF SOCIAL CONTROL IN RELATION TO PREVENTION OF WRONGFUL BEHAVIOUR AMONG YOUTHS
}

\begin{abstract}
Studies of European and American scholars have highlighted the low effectiveness of preventive social control. In Russia, such studies have yet to be conducted. Nonetheless, the negative tendencies of wrongful behaviour among youths suggest there are shortcomings in the current set of preventive measures. These tendencies include an increasing number of incidents, as well as the rejuvenating and feminisation of wrongful behaviour. The study of the reasons for the inefficiency of these preventive activities can also be carried out on the basis of analysis of assessments given by agents of social control. To do this, a constructivist approach to social control as a form of communication is employed. Studying this process entails deconstructing the rhetoric of various agencies of social control. The results of study are based on analysis of transcripts of interviews with experts. Representatives of the police, schools, state and non-state social protection organisations were interviewed. Their rhetoric was deconstructed concerning the interaction of agencies with preventive work concerning young people. The study showed that the current state of preventive activity is described by the agencies of control either through the idiom of danger or using disaster as the main leitmotif. For the police and school representatives, perception of the threat is tied to the ineffective activities of some institutions and the lack of interest shown by parents. They also used constructs revolving around the rhetoric of empowerment, which are associated with the expansion of the powers of the agencies of control. Representatives of social protection agencies more often use the leitmotifs of disaster in describing the state of preventive activity. They associate threats with the insufficient attention of the state to preventing wrongful behaviour among youth. This is reflected in insufficient financial support, ill-conceived laws, staff reduction, as well as unnecessarily strict controls over the activities of prevention subjects.
\end{abstract}

Keywords: prevention of wrongful behaviour, subjects of prevention, rhetoric, rhetorical reconstruction, rhetorical idioms, leitmotifs

DOI: 10.17323/727-0634-2019-17-4-525-538

\section{References}

Berger P., Luckman T. (1995) Social'noe konstruirovanie real'nosti. Traktat po sociologii znanija [The Social Construction of Reality. A Treatise on Sociology of Knowledge]. Moscow: Medium.

Tatiana V. Shipunova - Doctor of Social Sciences, Associate Professor, Professor, St. Petersburg University, St. Petersburg, Russian Federation. Email: shtatspb@yandex.ru 
Best J. (2001) Konstrukcionistskij podhod k issledovaniju social'nyh problem [A Constructionist Approach to the Study of Social Problems]. In: S. A. Erofeev (ed.) Konteksty sovremennosti-II: Hrestomatija. 2-e izd. [Contexts of Our Time - II: Reader. 2nd ed.]. Kazan: Izdatel'stvo Kazanskogo universiteta: 164-174.

Eisner M., Ribeaud D., Junger R., Meidert U. (2008) Frühprävention von Gewalt und Aggression. Ergebnisse des Züricher Interventions- und Präventionsprojektes an Schulen. Zürich: Rüegger Verlag.

Efimovskij A. V., Stebeneva E. V. (2015) Sovremennaja prestupnost': tendencii, prichiny, prognoz (na primere Sankt-Peterburga) [Modern Crime: Trends, Causes, Forecast (The Case of St. Petersburg)]. Vestnik Sankt-Peterburgskogo universiteta MVD Rossii [St. Petersburg Internal Ministry University Review], 1 (65): 82-86.

Upolnomochennyj po pravam cheloveka v Sankt-Peterburge (2016) Ezhegodnyj doklad upolnomochennogo po pravam rebenka $v$ Sankt-Peterburge za $2015 \mathrm{~g}$. [Annual Report of the Ombudsman for the Rights of Children in St. Petersburg in 2015]. St. Petersburg: Ombudsman Office in St. Petersburg.

Graham J., Bennett T. (1995) Strategii preduprezhdenija prestupnosti v Evrope i Severnoj Amerike [Strategies for Crime Prevention in Europe and North America]. Helsinki: Evropejskij institut po preduprezhdeniju prestupnosti i bor'be s nej.

Ibarra P., Kitsuse J.I. (2007) Diskurs vydvizhenija utverzhdenij-trebovanij i prostorechnye resursy [Claims-making Discourse and Vernacular Resources]. In: I. G. Jasaveev (ed.) Social'nye problemy: konstrukcionistskoe prochtenie [Social Problems: Constructional Reading]. Kazan: Izdatel'stvo Kazanskogo universiteta: 55-114.

Jasaveev I. (2016) Lejtmotivy vlastnoj ritoriki v otnoshenii rossijskoj molodjozhi [Leitmotifs of Power Rhetoric Towards Russian Youth]. Sociologicheskoe obozrenije [Russian Sociological Review], 3: 49-67.

Obrazhiev K. V. (2015) Prestupnost' nesovershennoletnih v sovremennoj Rossii: osnovnye kriminologicheskie parametry [Juvenile delinquency in modern Russia: the main criminological parameters]. Pravovaja iniciativa [The Legal Initiative], (2): 14-35.

Pfeifer Ch., Baier D. (2008) Jugendgewalt als Wahlkampfthema. Eine Kriminologische Analyse zum hessischen Landtagswahlkampf des Jahres. Interdisziplinäre Kriminologie. Festschrift für Arthur Kreuzer zum 70. Geburtstag. Zweiter Band. Frankfurt: Verlag für Polizeiwissenschaft: 550-574.

Sztompka P. (1996) Sociologija social'nyh izmenenij [The Sociology of Social Change]. Moscow: Aspekt Press.

Spector M., Kitsuse J.I. (2001) Konstruirovanie social'nyh problem [Constructing Social Problems]. In: S. A. Erofeev (ed.) Konteksty sovremennosti - II: Hrestomatija. 2-e izd. [Contexts of our time - II: Reader. 2nd ed.]. Kazan: Izdatel'stvo Kazanskogo universiteta: 160-163. 